\title{
LETTER
}

\section{GC/GC/C/IRMS system for carbon isotope measurement of low level methane concentration}

\author{
Atsuko Sugimoto \\ Center for Ecological Research, Kyoto University, 4-1-23 Shimosakamoto, Otsu, Shiga 520-01, Japan
}

(Received February 16, 1996; Accepted April 11, 1996)

\begin{abstract}
A flow-through system, GC/GC/C/IRMS (gas chromatograph/gas chromatograph/combustion/isotope ratio mass spectrometer) was developed for carbon isotope analysis of methane in a sample of low level concentration. In this system, methane was roughly separated from a large amount of $\mathrm{N}_{2}$ and $\mathrm{O}_{2}$ in the first $\mathrm{GC}$ with packed column, then introduced into GC/C/IRMS and carbon isotopic composition was measured. The $\delta^{13} \mathrm{C}$ of methane in a sample of $92 \mathrm{ml}$ in volume with concentration of $11 \mathrm{ppm}$ was successfully obtained with a standard deviation of $\pm 0.4 \%$.
\end{abstract}

\section{INTRODUCTION}

A flow-through system for the measurement of natural abundance ratios of carbon isotopes, $\mathrm{GC} /$ C/IRMS (gas chromatograph/combustion/isotope ratio mass spectrometer) has been developed (Matthews and Hayes, 1978; Merritt et al., 1994; Ricci et al., 1994) and applied to wide scientific fields (Freeman et al., 1990; Jasper and Hayes, 1990; Silfer et al., 1991). Isotope analysis using GC/C/IRMS has an advantage that can simplify procedures for purification of gas mixtures and combustion of hydrocarbons. GC/C/IRMS system has also been applied to carbon isotopic measurement of methane (Sugimoto et al., 1991; Zeng et al., 1994; Merritt et al., 1995), which has drawn scientific attention because of its efficiency as a greenhouse gas (Cicerone and Oremland, 1988). The carbon isotopic composition of $\mathrm{CH}_{4}$ has been analyzed to know the origin (Whiticar et al., 1986) or formation pathways of $\mathrm{CH}_{4}$ (Sugimoto and Wada, 1995). However, GC/C/IRMS could be applied to methane only for samples with high methane concentration (usually higher than 1000 $\mathrm{ppm})$, because the capillary column used in a GC/
C/IRMS restricts a gas volume which can be injected. The difficulty of complete separation of $\mathrm{CH}_{4}$ from air is another problem. A system which can be applied to low methane concentration such as flux chamber air or atmospheric methane has been desired. Merritt et al. (1995) developed a system for atmospheric $\mathrm{CH}_{4}$, in which $\mathrm{CH}_{4}$ was concentrated by chilling the column to $-118^{\circ} \mathrm{C}$. It is not easy, however, to control the column temperature at $-118^{\circ} \mathrm{C}$. I developed a system with a gas chromatograph for rough, preliminary separation of methane from a large volume of air combined to a GC/C/IRMS.

\section{Experimental Procedures}

The system developed in this study consists of two main components (Fig. 1). One is a gas chromatograph, GC(I), (Shimadzu GC-8A) with packed column of Molecular Sieves 5 A (MS-5A) (i.d. $5 \mathrm{~mm}, 5 \mathrm{~m}$ ) and TCD (thermal conductivity detector). A gas sampler (MGC-5, Shimadzu) with MS-5A loop to trap sample gas is attached to GC(I). The other component is GC/C/IRMS (Finnigan MAT deltaS/GC) with a capillary col- 


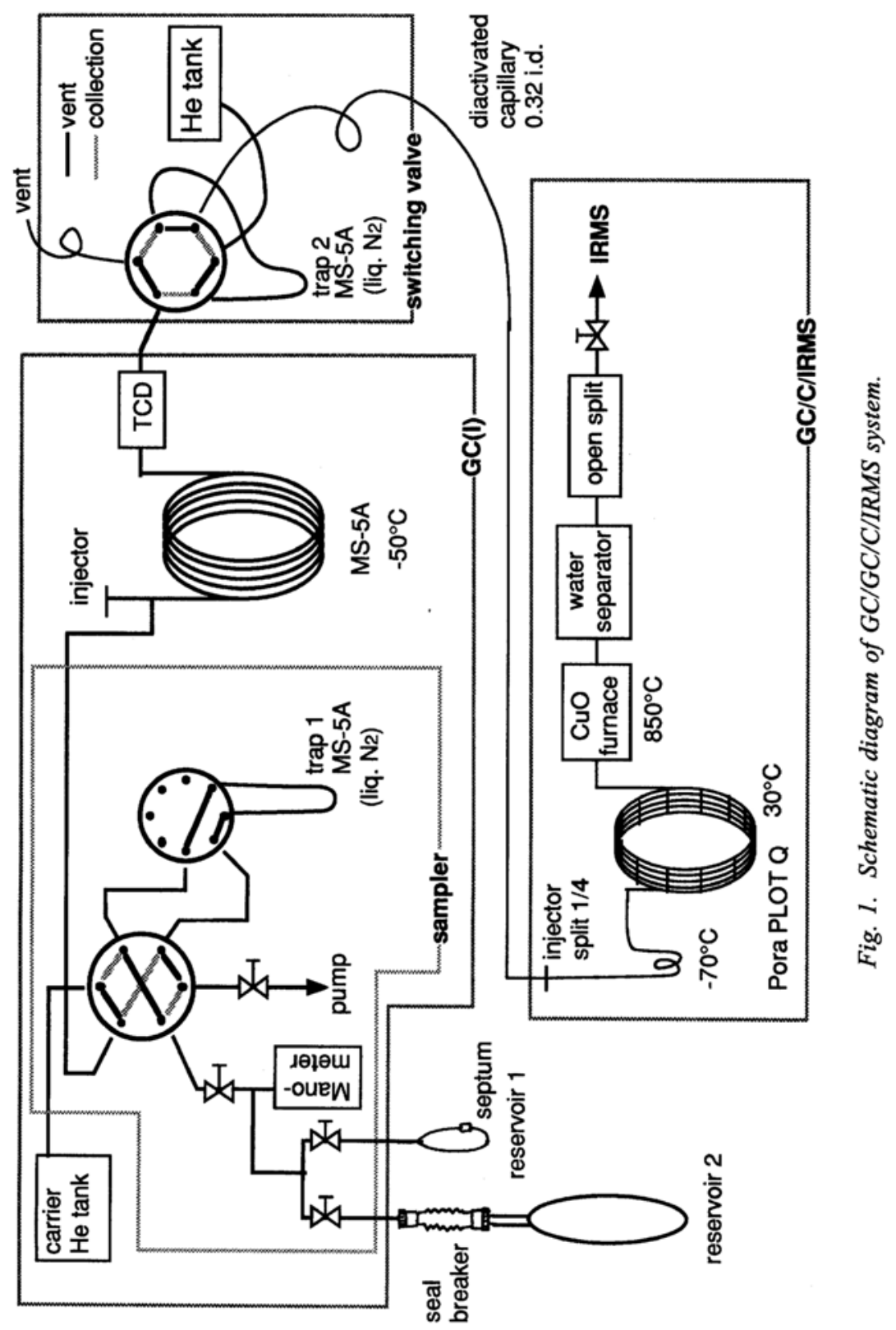




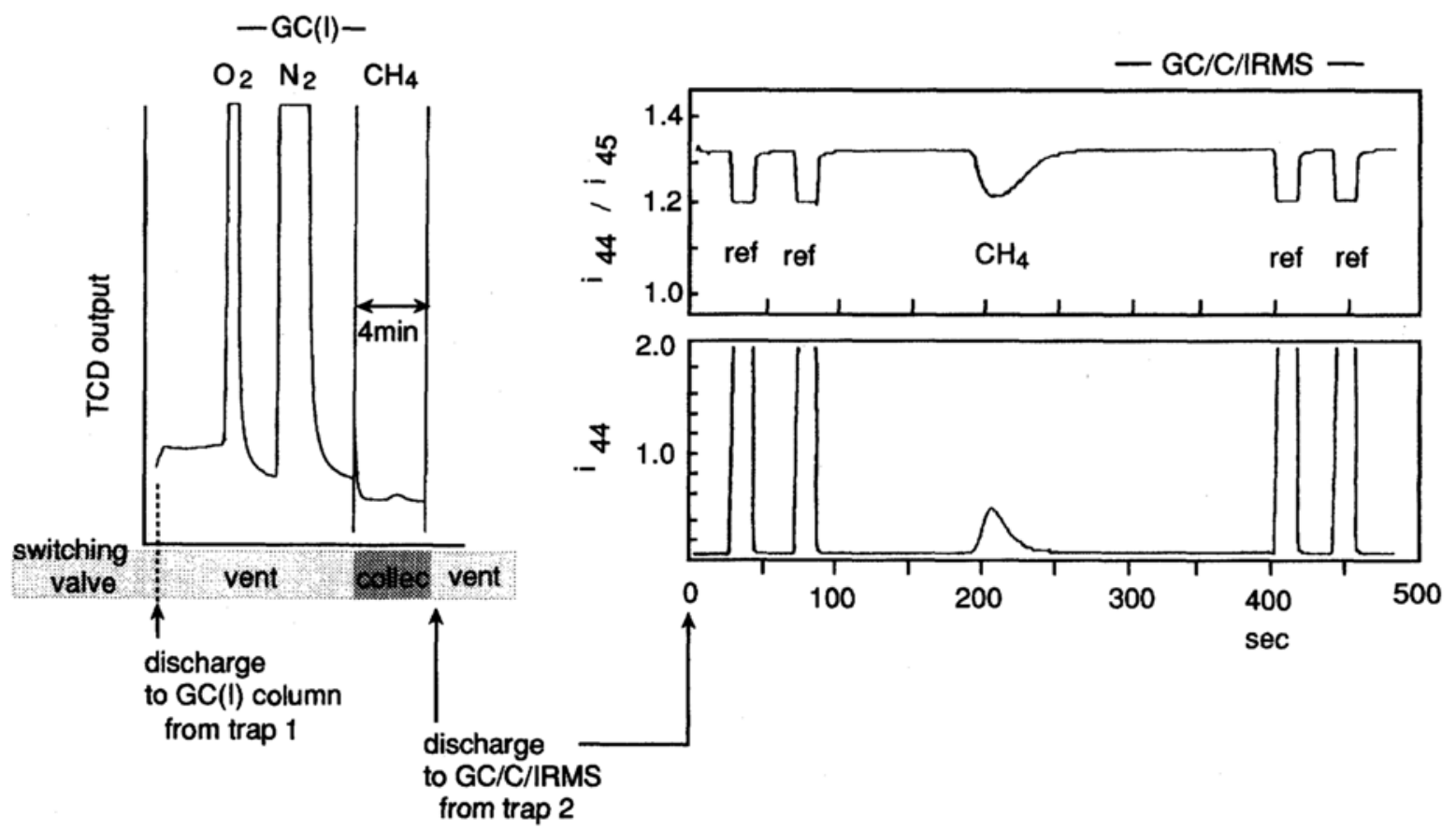

Fig. 2. Chromatographs of GC(I) and GC/C/IRMS. $10 \mathrm{ml}$ of sample gas (200 ppm) was injected from the reservoir 1 .

umn of Pora PLOT-Q (i.d. $0.32 \mathrm{~mm}, 25 \mathrm{~m}$ ). A switching valve with MS-5A loop is placed between $\mathrm{GC}(\mathrm{I})$ and $\mathrm{GC} / \mathrm{C} / \mathrm{IRMS}$ to switch the carrier gas flow from GC(I).

A required sample volume depends on the sensitivity of IRMS. The system used in this study needs 0.5 to $2 \mu \mathrm{l}$ or more of $\mathrm{CH}_{4}$ at room temperature and pressure (RTP) (21 to $83 \mathrm{nmol}$ ). Two standard gases containing $\mathrm{CH}_{4}$, st-A and st-B, were used to test the system. The concentration of $\mathrm{CH}_{4}$ was $1 \%$ for st-A and $2 \%$ for st-B, and nitrogen was balanced for both. Various methane concentrations were produced by mixing st-B and st-air ( $79 \% \mathrm{~N}_{2}$ and $21 \% \mathrm{O}_{2}$ mixture).

A sample gas was introduced from reservoir 1 or 2, and collected in trap 1 (MS-5A, at liquid $\mathrm{N}_{2}$ temperature). Before and during trapping sample gas, trap 1 was evacuated. It took about $5 \mathrm{~min}$ to collect sample gas to trap 1 . Then, the sample gas was discharged from trap 1 to the GC(I) column, by changing He flow through a 6-way valve and heating trap 1 with hot water. In the GC(I) col- umn $\mathrm{CH}_{4}$ was separated from $\mathrm{N}_{2}$ (Fig. 2). During $\mathrm{CH}_{4}$ flowing out of TCD, the switching valve was turned to "collection" to trap $\mathrm{CH}_{4}$ in a small MS5A loop (trap 2) at liquid $\mathrm{N}_{2}$ temperature. Other gases such as $\mathrm{O}_{2}, \mathrm{~N}_{2}$ and $\mathrm{CO}_{2}$ were vented out. The collected $\mathrm{CH}_{4}$ in trap 2 was, then, discharged to $\mathrm{GC} / \mathrm{C} / \mathrm{IRMS}$ by heating trap 2 with a hair-drier. Required time was 16 min for the separation in GC(I) and another $7 \mathrm{~min}$ for IRMS.

The results of carbon isotopic composition are expressed with $\delta^{13} \mathrm{C}$ values defined as follows:

$$
\delta^{13} \mathrm{C}=\left(\frac{R \mathrm{sa}}{R \mathrm{st}}-1\right) \times 1000(\%)
$$

where $R$ sa and $R$ st are isotope ratios $\left({ }^{13} \mathrm{C} /{ }^{12} \mathrm{C}\right)$ for sample and standard (PDB), respectively. In the GC/C/IRMS, $\delta^{13} \mathrm{C}$ values of samples were measured against a reference $\mathrm{CO}_{2}$ (Ricci et al., 1994). Since a shift of measured $\delta^{13} \mathrm{C}$ values of sample $\mathrm{CH}_{4}$ is sometimes observed, the $\delta^{13} \mathrm{C}$ values of samples are usually corrected by normalizing to 
the $\delta^{13} \mathrm{C}$ of a standard $\mathrm{CH}_{4}$ analyzed at the same condition as the samples (Sugimoto et al., 1991). However, the $\delta^{13} \mathrm{C}$ values before correction are considered in this paper, since the purpose of this study is to test the reproducibility of the system.

\section{RESULTS AND DISCUSSION}

\section{Separation of $\mathrm{CH}_{4}$ from air}

When the sample gas volume was greater than $20 \mathrm{ml}, \mathrm{CH}_{4}$ peak in $\mathrm{GC}(\mathrm{I})$ was on the tail of $\mathrm{N}_{2}$ peak. Consequently, the mixture of $\mathrm{CH}_{4}$ and $\mathrm{N}_{2}$ was introduced into GC/C/IRMS. If the separation of $\mathrm{CH}_{4}$ from $\mathrm{N}_{2}$ in the GC/C/IRMS capillary column was not perfect, the $\delta^{13} \mathrm{C}$ of $\mathrm{CH}_{4}$ was interfered with the noise signal of $45 / 44$ caused by $\mathrm{N}_{2}$ (Fig. 3). However, it is possible to separate $\mathrm{CH}_{4}$ from $\mathrm{N}_{2}$ by cooling the column. To analyze $\mathrm{CO}_{2}$ at the same time, Sugimoto et al. (1991) kept the column temperature at $0^{\circ} \mathrm{C}$, because the retention

(a)

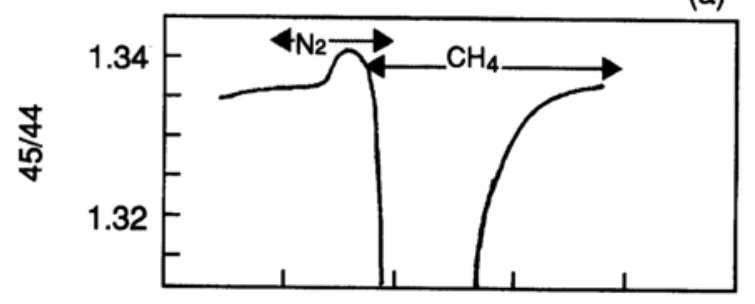

(b)

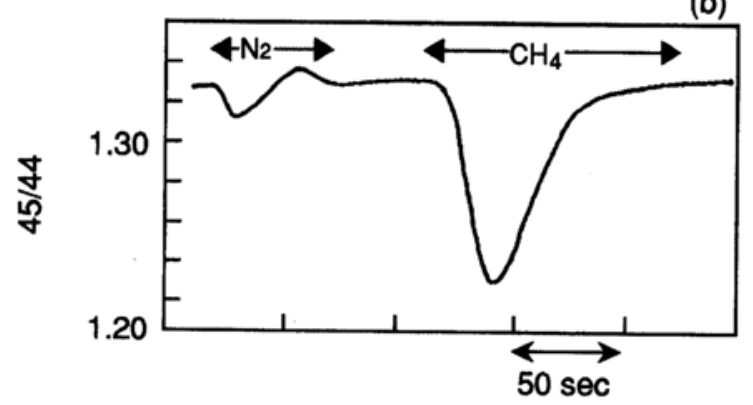

Fig. 3. 45/44 signal caused by $N_{2}$. When the sample volume is greater than $20 \mathrm{ml}, \mathrm{N}_{2}$ entered into $\mathrm{GC} / \mathrm{Cl}$ IRMS with $\mathrm{CH}_{4}$ produces signals of $45 / 44$ and 46/44, and interferes with the $\delta^{13} \mathrm{C}$ measurement for $\mathrm{CH}_{4}(a)$. The perfect separation of $\mathrm{CH}_{4}$ from $\mathrm{N}_{2}$ is achieved by keeping the small loop of the capillary column at about $-70^{\circ} \mathrm{C}(\mathrm{b})$. time of $\mathrm{CO}_{2}$ became much longer at lower temperatures. In the current system, since $\mathrm{CO}_{2}$ dose not enter into the GC/C/IRMS, small loop of the capillary column in GC/C/IRMS (about $60 \mathrm{~cm}$ long) was put into an ethanol/liquid $\mathrm{N}_{2}$ slush kept at about -60 to $-80^{\circ} \mathrm{C}$ to separate $\mathrm{CH}_{4}$ from $\mathrm{N}_{2}$.

\section{Combustion efficiency}

When combustion of $\mathrm{CH}_{4}$ is not complete, remaining $\mathrm{CH}_{4}$ causes a deviation of $\delta^{13} \mathrm{C}$ depending on the pressure in IRMS due to the isotope fractionation during the combustion and the reaction among ionized molecules derived from $\mathrm{CO}_{2}$ and $\mathrm{CH}_{4}$ in the ionization chamber (Sugimoto et al., 1991; Zeng et al., 1994). Using the current system, $\mathrm{CH}_{4}$ was completely combusted at furnace temperatures higher than $830^{\circ} \mathrm{C}$. The combustion was, therefore, done at $850^{\circ} \mathrm{C}$.

\section{Sensitivity}

The $\delta^{13} \mathrm{C}$ of st-A $\left(1 \% \mathrm{CH}_{4}\right)$ was measured for $\mathrm{CH}_{4}$ with the absolute amount of 0.5 to $3 \mu \mathrm{l}$ at RTP (50 to $300 \mu \mathrm{l}$ of injection volume). When the amount of $\mathrm{CH}_{4}$ was $3 \mu \mathrm{l}$, the standard deviation of $\delta^{13} \mathrm{C}$ was less than $\pm 0.3 \%$ (Fig. 4). The reproducibility was low with small sample volumes due to the sensitivity of IRMS. When the amount of $\mathrm{CH}_{4}$ was less than $1 \mu \mathrm{l}$, a shift of $\delta^{13} \mathrm{C}$ and increasing standard deviation were sometimes observed with decreasing the amount of $\mathrm{CH}_{4}$. The direction of $\delta^{13} \mathrm{C}$ shift varied case by case. In many cases, however, $\delta^{13} \mathrm{C}$ of $\mathrm{CH}_{4}$ decreased with decreasing the amount of $\mathrm{CH}_{4}$, whereas, the $\delta^{13} \mathrm{C}$ of $\mathrm{CO}_{2}$ increased with decrease of the amount of $\mathrm{CO}_{2}$. Such a shift of $\delta^{13} \mathrm{C}$ with decrease of the sample amount may be caused by the reaction with $\mathrm{H}_{2} \mathrm{O}$ in the ion source of IRMS, since the $\delta^{13} \mathrm{C}$ shift was eliminated by baking the capillary column. The GC/GC/C/IRMS for low level concentration of $\mathrm{CH}_{4}$ was, therefore, tested using 1 and 2 $\mu \mathrm{l}$ of $\mathrm{CH}_{4}$.

\section{Test for low level concentration of $\mathrm{CH}_{4}$}

The samples of the mixture of st-B and $\mathrm{N}_{2} / \mathrm{O}_{2}$ with the concentration of 200 to $11 \mathrm{ppm} \mathrm{CH}_{4}(10$ to $92 \mathrm{ml}$ in the volume) were tested. The gas 
volume less than $50 \mathrm{ml}$ can be introduced into the GC(I) column at once. Accordingly, when a sample volume was greater than $50 \mathrm{ml}$, the sample was divided into some fractions at the sampler. The $\mathrm{CH}_{4}$ from each fraction was then collected in trap 2 and introduced into GC/C/IRMS at once. The $\delta^{13} \mathrm{C}$ of $\mathrm{CH}_{4}$ was successfully measured for the concentration down to $11 \mathrm{ppm}$ with a standard deviation of $\pm 0.4 \%$ (Table 1). The procedure with trap 2 is essential for samples with low $\mathrm{CH}_{4}$ concentration. In the case of high $\mathrm{CH}_{4}$ concentration, it is possible to analyze $\delta^{13} \mathrm{C}$ without trap 2, because the peak of $\mathrm{CH}_{4}$ flowed out of $\mathrm{GC}(\mathrm{I})$ is not broad. While, for samples with low $\mathrm{CH}_{4}$ concentration, in other words large sample volume, the peak width of $\mathrm{CH}_{4}$ from $\mathrm{GC}(\mathrm{I})$ was broader than 1 min (Fig. 2), and $\mathrm{CH}_{4}$ needs to be concentrated at trap 2 .

The sensitivity of GC/C/IRMS used in this study is not high enough for the analyses of the

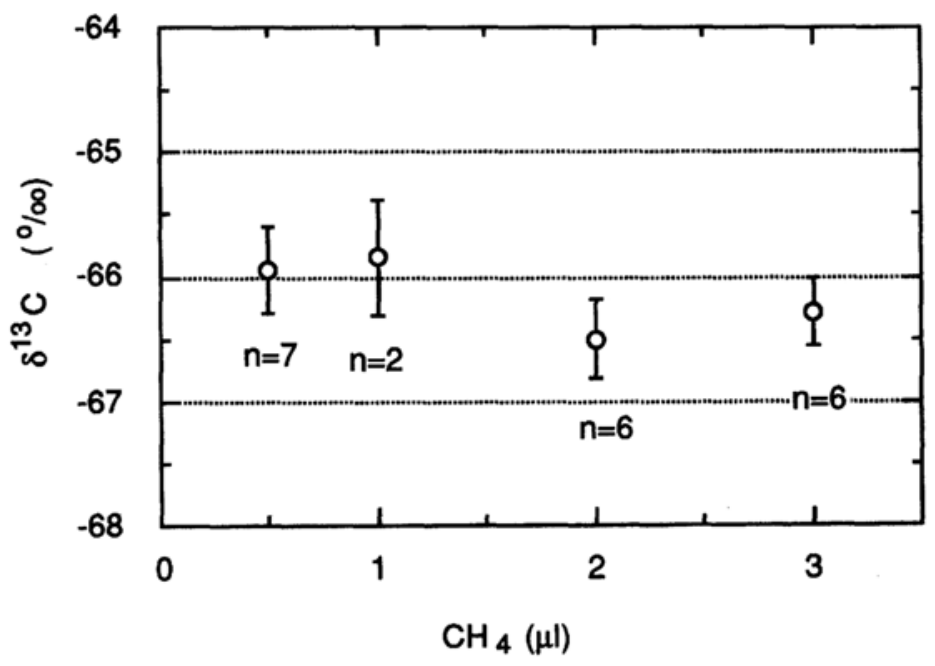

Fig. 4. $\delta^{3} \mathrm{C}$ values and standard deviations for $\mathrm{CH}_{4}$ with the absolute amount of 0.5 to $3 \mu$ at $\mathrm{RTP} .50$ to 300 $\mu l$ of $s t-A$ was injected.

Table 1. $\delta^{13} \mathrm{C}_{\text {of }} \mathrm{CH}_{4}$ for st-B obtained in the experiment with low level $\mathrm{CH}_{4}$ concentration

\begin{tabular}{cccc}
\hline $\mathrm{CH}_{4}(\mu \mathrm{l})^{*}$ & $\delta^{13} \mathrm{C}(\%)$ & Concentration $(\mathrm{ppm})$ & Volume $(\mathrm{ml})$ \\
\hline 2 & -66.3 & 200 & 10 \\
2 & -66.0 & 100 & 20 \\
1 & -66.4 & 100 & 10 \\
1 & -65.3 & 50 & 20 \\
2 & -65.9 & 200 & 10 \\
1 & -65.6 & 100 & 10 \\
1 & -65.5 & 11 & 92 \\
1 & -65.4 & 11 & 92 \\
\hline Ave. & -65.8 & & \\
st.dev. & \pm 0.4 & & \\
\hline
\end{tabular}

*The absolute amount of $\mathrm{CH}_{4}$ in a sample gas at $\mathrm{RTP}$. 
atmospheric $\mathrm{CH}_{4}$ with concentration of $2 \mathrm{ppm}$. It is possible, however, to analyze atmospheric $\mathrm{CH}_{4}$, if the sample gas is divided into several fractions before introducing into $\mathrm{GC}(\mathrm{I})$, or if a GC/C/IRMS with more sensitive IRMS is used. The concentration of $\mathrm{CH}_{4}$ handled in this study (>10 ppm) is equivalent to that observed in a flux chamber air or incubation experiments for various $\mathrm{CH}_{4}$ sources. Accordingly, GC/GC/C/IRMS developed in this study can be applied to $\delta^{13} \mathrm{C}$ measurement of $\mathrm{CH}_{4}$ in various fields.

Acknowledgments-The author thanks Mr. Howard Mendlovitz for his helpful advise on the method of GC capillary column cooling. This work was supported by a grant from The Nippon Life Insurance Foundation.

\section{REFERENCES}

Cicerone, R. J. and Oremland, R. S. (1988) Biogeochemical aspects of atmospheric methane. Global Biogeochem. Cycles 2, 299-327.

Freeman, K. H., Hayes, J. M., Trendel, J.-M. and Albrecht, P. (1990) Evidence from carbon isotope measurements for diverse origins of sedimentary hydrocarbons. Nature 343, 254-256.

Jasper, J. P. and Hayes, J. M. (1990) A carbon isotope record of $\mathrm{CO}_{2}$ levels during the late Quaternary. Nature 347, 462-464.

Matthews, D. E. and Hayes, J. M. (1978) Isotope-ratiomonitering gas chromatograph-mass spectrometry. Anal. Chem. 50, 1465-1473.

Merritt, D. A., Brand, W. A. and Hayes, J. M. (1994)
Isotope-ratio-monitering gas chromatography-mass spectrometry: methods for isotopic calibration. Org. Geochem. 21, 573-583.

Merritt, D. A., Hayes, J. M. and Marais, D. J. D. (1995) Carbon isotopic analysis of atmospheric methane by isotope-ratio monitoring gas chromatography-mass spectrometry. J. Geophys. Res. 100D1, 1317-1326.

Ricci, M. P., Merritt, D. A., Freeman, K. H. and Hayes, J. M. (1994) Acquisition and processing of data for isotope-ratio-monitoring mass spectrometry. Org. Geochem. 21, 561-571.

Silfer, J. A., Engel, M. H., Macko, S. A. and Jumeau, E. J. (1991) Stable carbon isotope analysis of amino acid enantiomers by conventional isotope ratio mass spectrometry and combined gas chromatography/ isotope ratio mass spectrometry. Anal. Chem. 63, 370-374.

Sugimoto, A., Hong, X. and Wada, E. (1991) Rapid and simple measurement of carbon isotope ratio of bubble methane using GC/C/IRMS. Mass Spectroscopy 39, 261-266.

Sugimoto, A. and Wada, E. (1995) Hydrogen isotopic composition of bacterial methane: $\mathrm{CO}_{2} / \mathrm{H}_{2}$ reduction and acetate fermentation. Geochim. Cosmochim. Acta 59, 1329-1337.

Whiticar, M. J., Faber, E. and Schoell, M. (1986) Biogenic methane formation in marine and freshwater environments: $\mathrm{CO}_{2}$ reduction vs. acetate fermentation-isotope evidence. Geochim. Cosmochim. Acta 50, 693-709.

Zeng, Y., Mukai, H., Bandow, H. and Nojiri, Y. (1994) Application of gas chromatograph-combustion isotope ratio mass spectrometry to carbon isotopic analysis of methane and carbon monoxide in environmental samples. Analytica Chim. Acta 289, 195204. 